\title{
Endotracheal cuff pressures in the PICU: Incidence of underinflation and overinflation
}

\author{
Richard W. Wettstein MMEd, RRT, FAARC ${ }^{1}$, Donna D. Gardner DrPH, RRT, FAARC ${ }^{2}$, Sadie Wiatrek MSRC, RRT ${ }^{1}$, \\ Kristina E. Ramirez MPH, RRT, CHES ${ }^{1}$, Ruben D. Restrepo MD, RRT, FAARC
}

\begin{abstract}
RW Wettstein, DD Gardner, S Wiatrek, KE Ramirez, RD Restrepo. Endotracheal cuff pressures in the PICU: Incidence of underinflation and overinflation. Can J Respir Ther 2020;56:1-4. doi: 10.29390/cjrt-2019-018.

Background: While uncuffed endotracheal tubes have been traditionally used in the pediatric intensive care unit (PICU) population, evidence suggests cuffed endotracheal tubes (ETTs) are also safe to use within this population. Nevertheless, risks related to the use of cuffed ETTs increase when guidelines for safe and appropriate use are not followed. The primary goal of this study was to measure the cuff pressure (CP) using a cuff pressure manometer in a group of intubated pediatric subjects and determine the rate of cuff underinflation $\left(<20 \mathrm{~cm} \mathrm{H}_{2} \mathrm{O}\right)$ or overinflation $\left(>30 \mathrm{~cm} \mathrm{H}_{2} \mathrm{O}\right)$. The secondary aim was to determine whether CP was associated to gender, age, ETT size, and PICU length of stay prior to CP measurement.

Methods: This was a prospective observational study conducted in an urban PICU. Pediatric subjects intubated with cuffed ETTs from 1 April 2017 to 1 May 2017 were included in the study. ETT CPs were measured daily to determine degree of inflation and compared according to gender, age, ETT size, and number of days intubated prior to CP measurement. Descriptive data are expressed as means and standard deviations. A two-sample $t$ test was used to compare groups according to age, gender, and number of days present. And significance was considered with a $P<0.05$. Pearson chi test was used to evaluate correlation between CPs and size of the ETT, number of days intubated prior to CP measurement, gender, and age.

Results: Twenty pediatric subjects admitted during the study period were included for analysis. Eleven cuff measurements were found to be within normal limits, while 9 cuff measurements were found to be underinflated. No cases of overinflation were found. There were no significant associations between CP and size of the ETT $(r=-0.08)$, number of days intubated prior to CP measurement $(r=0.19)$, gender $(r=0.09)$, and age $(r=0.12)$.

Conclusions: Our study suggests that endotracheal cuff underinflation occurs often in the PICU population. Strategies to ensure appropriate ETT CPs are maintained are essential in the intubated pediatric population. Additional studies are necessary to develop interventions and training focused on the use of a cuff pressure manometer to measure CPs in the PICU by respiratory therapists and ensure consistent measurement using inter rater evaluation processes are needed.
\end{abstract}

Key Words: pediatric airway; cuff management; airway injury; cuff underinflation

\section{INTRODUCTION}

Endotracheal intubation is a routine procedure for critical care management in the pediatric population to protect the airway, for bronchial hygiene, and to provide mechanical ventilation. Historically, uncuffed endotracheal tubes (UETT) have been recommended in pediatric subjects $<8$ years of age $[1,2]$. The landmark study by Khine et al. [3] conducted in the operating room over 20 years ago used the Microcuff (Kimberly-Clark) cuffed endotracheal tubes (CETT) and stressed the importance of using the appropriate size endotracheal tube (ETT) and recommended strict monitoring of cuff pressures (CPs).

Since then, improvements in ETT design have resulted in several studies that support the use of CETT $[4,5]$. Using CETT can improve control of ventilation/oxygenation, decrease risk of aspiration [6], and decrease the rate of postextubation stridor [2, 7]. A recent meta-analysis showed that while complications occur at the same rate with UETT and CETT, there is an increased need for reintubation with the use of UETT [8]. The 2016 American Heart Association (AHA) guidelines for pediatric advanced life support recommend CETT as a safe alternative to UETT [9].

Despite the transition to use of CETT in the pediatric population, limited research has been published related to the optimal CP and how best and how often to measure CP in the pediatric intensive care unit (PICU) [10, 11]. A number of methods are used to assess CP.
Many respiratory therapists (RTs) estimate CP by auscultation of the air leak. Air is slowly injected into the ETT pilot balloon until the air leak is no longer heard. This is the minimal occluding volume (MOV). On the other hand, the minimal leak technique (MLT) is similar to the MOV, yet a volume of air is slowly withdrawn from the inflated cuff, while auscultating over the trachea until a leak is heard and this is recorded as the MLT. At which time air is then added to stop the cuff leak [12]. The MLT and MOV are methods routinely used in ICUs, but often result in higher CP when compared with those obtained by cuff pressure manometer [12]. Pilot balloon palpation grossly estimates CP anywhere from 6 to $60 \mathrm{~cm} \mathrm{H}_{2} \mathrm{O}[13,14]$. Direct measurement with a cuff pressure manometer has been considered the "gold standard" method to monitor CP [15] as other methods that estimate the CP have been shown to be unreliable and often result in excessive CPs [15].

Taylor et al. [16] suggested use of high-volume low cuff pressure ETT can efficiently seal the airway at pressure of $\leq 15 \mathrm{~cm} \mathrm{H}_{2} \mathrm{O}$ without an increase in complications. Despite current AHA recommendations of maintaining $\mathrm{CP}$ at $\leq 20-25 \mathrm{~cm} \mathrm{H} \mathrm{O}$ [9], Tobias and associates [11, 17] continue to recommend the use of $\mathrm{CP} 20-30 \mathrm{~cm} \mathrm{H}_{2} \mathrm{O}$ as the rule until evidence clearly delineates a more appropriate range.

A recent survey of members of the Society of Pediatric Anesthesia reported that the most common reason for avoiding CETT in PICUs

\footnotetext{
${ }^{1}$ Division of Respiratory Care, The University of Texas Health Science Center at San Antonio, San Antonio, TX;

${ }^{2}$ Department of Respiratory Care, Texas State University, Round Rock, TX

Correspondence: Richard W. Wettstein, MMEd, RRT, FAARC, Division of Respiratory Care, Mail Code 6248, The University of Texas Health Science Center at San Antonio7703 Floyd Curl Dr. San Antonio, TX 78229-3900. Tel: (210) 567 7966, E-mail:wettstein@uthscsa.edu
}

Published online at https://www.cjrt.ca on 21 January 2020 
was the risk of postextubation stridor. Yet about $50 \%$ of the respondents inflate the cuff until a leak is present at $15-20 \mathrm{~mm} \mathrm{Hg}$ inflation pressure and more than $60 \%$ of respondents did not monitor CPs [18].

The primary goal of this study was to measure the CP using a cuff pressure manometer in a group of intubated pediatric subjects in the PICU at a university-affiliated institution and determine the rate of either cuff underinflation or overinflation. The secondary goal was to determine if $\mathrm{CP}$ outside the normal limits was associated with gender, age, ETT size, and number of days intubated prior to $\mathrm{CP}$ measurement.

\section{MATERIALS AND METHODS}

This was a prospective observational study performed at a universityaffiliated, 496-bed hospital, in San Antonio, Texas. The study was approved by The Institutional Review Boards at the University of Texas Health Science Center at San Antonio and University Health System. All subjects admitted to the PICU from 1 April 2017 through 1 May 2017, who required endotracheal intubation with CETT, and had mechanical ventilation were eligible for inclusion. Subjects with airway deformities, those with tracheostomy tubes, or those only intubated during surgical procedures in the PICU and then extubated, as well as those receiving high-frequency oscillatory ventilation were excluded. Data were collected during the 7:00 AM to 7:00 PM shift.

CP is routinely estimated by the PICU unit RT at least once every 12-h shift using the MLT. The process the PICU unit RT used for evaluating the ETT CP was as follows. The patient was positioned supine, the volume of air in the ETT cuff was first ascertained by slowly withdrawing air from the cuff using a 10-cc syringe while auscultating over the trachea until a leak was heard, and at this point the MLT was recorded. After routine assessment by the PICU unit RT in charge of a study subject, the $\mathrm{CP}$ was measured once by a research RT at the end of expiration using a Cufflator (Posey, Arcadia, CA) attached to the pilot balloon of the ETT. The same cufflator was used for the study. The PICU unit RT in charge of the study patient was not blinded to the research teams' CP measurements. $\mathrm{CP}$ values $<20 \mathrm{~cm} \mathrm{H} \mathrm{H}_{2} \mathrm{O}$ were considered underinflated and $>30 \mathrm{~cm} \mathrm{H} \mathrm{H}_{2} \mathrm{O}$ were considered overinflated. When the $\mathrm{CP}$ was determined to be out of range, the research RT would adjust the CP to the recommended range $\left(20-30 \mathrm{~cm} \mathrm{H}_{2} \mathrm{O}\right)$, notify the PICU unit RT in charge of the patient, and document in the patient's chart. Subject demographic data (i.e., gender, age), size of ETT, reason for intubation, and ICU duration prior to CP measurement were recorded. Cuff pressure measurements were compared between groups according to age, gender, size of ETT, and number of days intubated prior to CP measurement. A comparison was made between CP recorded in subjects $\leq 8$ years age (old "cut-off" age for using of UETT) and $>8$ years $[1,2]$.

\section{Statistical analysis}

All statistical analyses were performed using IBM SPPS Statistics v.25 (Chicago, IL). Descriptive data are expressed as means and standard deviations. A two-sample $t$ test was used to compare groups according to age $(\leq 8$ years of age vs. $>8$ years of age) and gender and number of days intubated $(\leq 1$ week vs. $>1$ week). Significance was considered with $P<0.05$. Pearson chi square test was used to evaluate correlation between $\mathrm{CP}$ and size of the ETT, number of days intubated prior to $\mathrm{CP}$ measurement, gender, and age.

\section{RESULTS}

During the study period 20 intubated pediatric subjects were admitted to the PICU. Of the 20 pediatric subjects, $40 \%$ were male $(n=8)$ and $60 \%$ female $(n=12), 75 \%$ were $\leq 8$ years of age $(1.2 \pm 1.96)$. The most common indications for intubation in this group were post-surgical care (45\%), followed by airway protection (35\%), and ventilatory failure (20\%). The mean $\mathrm{CP}$ was $17.95 \mathrm{~cm} \mathrm{H}_{2} \mathrm{O}(\mathrm{SD} \pm 3.92$; IQR 20; range: $10-24)$. The mean ETT size was $4.5 \mathrm{~mm}( \pm 1.3)$.

Forty-five percent of the cuffs $(n=9)$ were underinflated $\left(14.3 \pm 2.7 \mathrm{~cm} \mathrm{H}_{2} \mathrm{O}\right)$, whereas 11 cuffs $(55 \%)$ had a normal CP

\section{TABLE 1}

Patient characteristics by gender

\begin{tabular}{lccc}
\hline & Total & Male & Female \\
\hline Total, $n(\%)$ & $20(100)$ & $8(40)$ & $12(60)$ \\
Cuff pressure mean, $(\mathrm{SD})$ & $17.95( \pm 3.2)$ & $18.5( \pm 3.66)$ & $17.58( \pm 4.21)$ \\
$\leq 8$ years of age, $n(\%)$ & $15(75)$ & $5(33.3)$ & $10(66.7)$ \\
$>8$ years of age, $n(\%)$ & $5(25)$ & $3(60)$ & $2(40)$ \\
Endotracheal tube size, mean $(\mathrm{SD})$ & $4.5( \pm 1.3)$ & $5.1(1.64)$ & $4.1(0.93)$ \\
Total intubated $>1$ week, $n(\%)$ & $9(45)$ & $4(44.4)$ & $5(55.6)$ \\
Total intubated $<1$ week, $n(\%)$ & $11(55)$ & $4(36.4)$ & $7(63.6)$ \\
Reason for intubation, $n(\%)$ & & & \\
Airway protection & $7(35)$ & $5(71.4)$ & $2(18.6)$ \\
Respiratory failure & $4(20)$ & $2(50)$ & $2(50)$ \\
Post-surgery & $9(45)$ & $1(11.1)$ & $8(89.9)$ \\
\hline
\end{tabular}

\section{FIGURE 1.}

Measured cuff pressures for each subject.

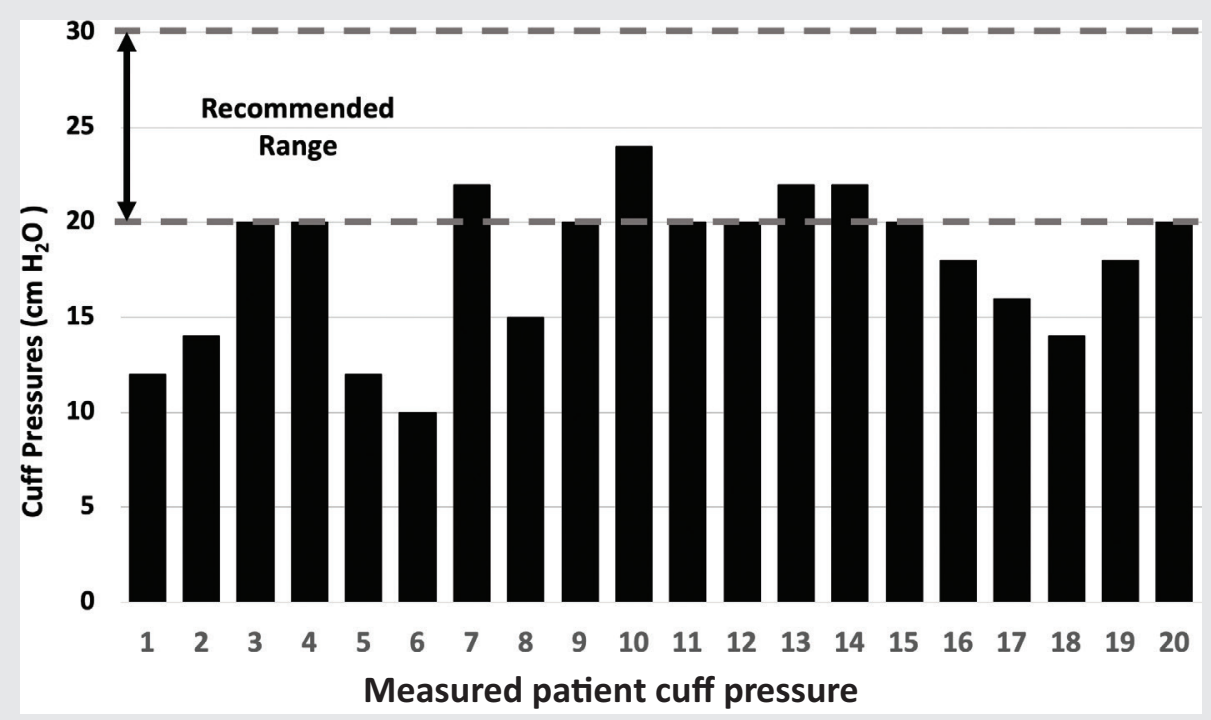


$(20.1 \pm 1.37)$. None of the cuffs were overinflated $\left(\mathrm{CP}>30 \mathrm{~cm} \mathrm{H} \mathrm{H}_{2} \mathrm{O}\right)$ (see Figure 1).

There was not a significant difference between mean CP (in $\left.\mathrm{cm} \mathrm{H}_{2} \mathrm{O}\right)$ in males $(18.5( \pm 3.66))$ and females $(17.58( \pm 4.21))(P=0.62), \leq 8$ years of age or younger $(20.2 \pm 4.0)$ and those $>8$ years of age $(19.6 \pm 2.6)$ $(P=0.14)$, and the number of days intubated prior to measurement of CP (>1 week: $18.58 \pm 3.85)$ and $<1$ week: $17.56 \pm 4.22 ; P=0.70)$. Table 1 summarizes patient characteristics by gender.

There were no significant associations between $\mathrm{CP}$ and size of the ETT $(r=[0.08)$, number of days intubated prior to CP measurement $(r=0.19)$, gender $(r=0.09)$, and age $(r=0.12)$.

\section{DISCUSSION}

The majority of ETT CPs measured in this study were found to fall within the recommended range, with the remainder being underinflated in the PICU. Underinflation rates in our study (45\%) were similar to those reported by Valencia et al. [19] $(45.3 \% ; n=33)$ after evaluating CP in adult ventilated subjects in semi-recumbent position in the adult ICU. Harvie et al. [12] (24\% underinflation rate) also measured using the MLT in mechanically ventilated adults in in the supine position at 30-degree head up. Other literature suggested that normal to low CP may be better than excessively high $\mathrm{CP}$ as injury is less likely to occur when $\mathrm{CP}$ was maintained at $\leq 20 \mathrm{~cm} \mathrm{H}_{2} \mathrm{O}$ while maintaining adequate ventilation [12, 20, 21].

However adverse events are associated with inadequate CP $(<20 \mathrm{~cm}$ $\mathrm{H}_{2} \mathrm{O}$ ) [20-22]. Underinflation carries the risk of air leaks and unplanned extubation. Pediatric patients that are intubated and mechanically ventilated for more than $48 \mathrm{~h}$ are at risk for developing ventilator-associated pneumonia $[23,24]$. The aspiration of subglottic secretions colonized by bacteria pool around the ETT cuff and, due to cuff underinflation or by deflation move into the lungs, appear to play a relevant role in the pathogenesis of ventilator-associated pneumonia [25].

Our results differ considerably from several studies reporting that even experienced practitioners tend to overinflate ETT cuffs of pediatric subjects to pressures as high as $90 \mathrm{~cm} \mathrm{H}_{2} \mathrm{O}$ when no direct methods of measurement are used $[15,17]$. The differences in overinflation may be due to the patient population in the studies were surgical or paresthesia patients. In addition, Felten et al. [26], reported significant unpredictability of CP when using small cuffed ETTs during paranesthesia. Tollefsen et al. [27] reported that a pediatric transport team measured ETT CP upon arrival at the bedside. They found an overinflation rate of $41 \%$ with $30 \%$ of the cuffs inflated twice that recommended $\left(>60 \mathrm{~cm} \mathrm{H}_{2} \mathrm{O}\right)$ [27]. Gilliland et al. [28] evaluated recently intubated ETT CP of 96 adults undergoing general anesthesia and found that $64.6 \%$ of ETT cuffs were overinflated. Mean recorded CP was $47.5 \mathrm{~cm} \mathrm{H}_{2} \mathrm{O}$ (range $10-20 \mathrm{~cm} \mathrm{H}_{2} \mathrm{O}$ ). Tobias et al. [17] reported that $23.5 \%$ of the 200 pediatric ETT cuffs were overinflated $\left(>30 \mathrm{~cm} \mathrm{H}_{2} \mathrm{O}\right)$ in their study in the operating rooms of a tertiary care children's hospital.

These excessive CPs $\left(>30 \mathrm{~cm} \mathrm{H}_{2} \mathrm{O}\right)$ can inhibit capillary blood flow in the tracheal mucosa leading to mucosal injury and possible stenosis [18-20, 29]. Other injuries include tracheal rupture, necrosis, tracheo-esophageal fistula, postextubation stridor, and sore throat [29]. Postextubation stridor accounts for $25 \%-33 \%$ of failed extubations in the PICU [7].

Although CPs are usually assessed immediately after intubation, or after the ETT has been repositioned, they can drop between 6 and $20 \mathrm{~cm}$ $\mathrm{H}_{2} \mathrm{O}$ between scheduled monitoring times [10,30]. This suggests that closely monitoring CETTs may prevent the adverse effects mentioned above. However further study is required to determine just how often $\mathrm{CP}$ monitoring should be done, as a recent study by Letvin et al. [30] found that frequent $\mathrm{CP}$ monitoring was not associated with clinical outcome benefit compared with infrequent monitoring.

In our study there was not a significant difference between mean $\mathrm{CP}$ in subjects younger versus older than 8 years of age. Our results are opposed by Tobias [11], who found an increased incidence of an intracuff pressure $\geq 30 \mathrm{~cm} \mathrm{H}_{2} \mathrm{O}$ in subjects who were $>8$ years of age. Similarly, the number of days intubated ( $>1$ week or $<1$ week) was not found to correlate with $\mathrm{CP}$, although this would allow for more opportunities to measure CP and could reduce the rate of overinflation.

There are several limitations associated with this study. The sample size is small as it represented a cohort of subjects admitted to the PICU in 1 month; therefore, the results obtained cannot be generalized to a larger population or a different institution. Because the study subjects' CPs were only assessed on weekdays between 1 April 2017 and 1 May 2017 (total 21 days) during the day shift by a member of the research team and the study subjects were cared for by different RTs, it is difficult to determine CP measured when the research team was not present in the PICU during the night shift or on weekends. Despite these limitations, our results report similar rates of underinflation of studies with a larger sample size. There is a very limited number of trials focused on the actual measurement of CP in intubated pediatric subjects being mechanically ventilated in the PICU. This study provides results that need to be explored in further detail and in a much larger population.

\section{CONCLUSION}

Our data suggest that endotracheal cuff underinflation occurs often in the pediatric population. Strategies to ensure that appropriate ETT CPs are maintained are essential in the intubated pediatric population. Additional studies are necessary to develop interventions and training focused on the use of a cuff pressure manometer to measure CPs in the pediatric ICU by RTs and ensure consistent measurement using interrater evaluation processes are needed.

\section{ACKNOWLEDGMENTS}

The support of University Hospital - University Hospital System was integral to the completion of this study.

\section{CONTRIBUTORS}

All authors contributed to the conception or design of the work, the acquisition, analysis, or interpretation of the data. All authors were involved in drafting and commenting on the paper and have approved the final version.

\section{FUNDING}

This study did not receive any specific grant from funding agencies in the public, commercial, or not-for-profit sectors.

\section{COMPETING INTERESTS}

All authors have completed the ICMJE uniform disclosure form at www. icmje.org/coi_disclosure.pdf and declare: no financial relationships with any organizations that might have an interest in the submitted work in the previous 3 years; no other relationships or activities that could appear to have influenced the submitted work.

\section{REFERENCES}

1. Motoyama EK. The shape of the pediatric larynx: Cylindrical or funnel shaped? Anesth Analg 2009;108(5):1379-81. doi: 10.1213/ane.0b013 d31819ed494.

2. Jang M, Basa K, Levi J. Risk factors for larngeal trauma and granuloma formation in pediatric intubations. Int J Ped Otorhinolaryngol 2018;107: 45-52. doi: 10.106/j.ijporl.2018.01.008.

3. Khine HH, Corddry DH, Kettrick RG, et al. Comparison of cuffed and uncuffed endotracheal tubes in young children durin general anesthesia. Anesthesiology 1997;86(3):627-31. doi: 10.1097/00000542-19970300000015.

4. Mukhopadhyay S, Bhattacharya D, Bandyopadhyay BK, Mukherjee M, Ganguly R. Clinical performance of cuffed versus uncuffed preformed endotracheal tube in pediatric patients undergoing cleft palate surgery. Saudi J Anaesth 2016;10(2):202-7. doi: 10.4103/1658=354X.168842.

5. Rafiq M, Wani T, Moore-Clingenpeel M, Tobias JD. Endotracheal tubes and the cricoid: Is there a good fit? Int J Pediatr Otorhinolaryngol 2016;85:8-11. doi: 10.1016/j.ijporl.206.03.016.

6. DeMichele JC, Vajaria N, Wang H, Sweeney DM, Powers KS, Cholette JM. Cuffed endotracheal tubes in neonates and infants undergoing cardiac surgery are not associated with airway complications. J Clin Anesth 2016;33:422-7. doi: 10.1016/j.jclinane.2016.04.038.

7. Schneider J, Mulale U, Yamout S, Pollard S, Silver P. Impact of monitoring endotracheal tube cuff leak pressure on postextubation stridor in children. J Crit Care 2016;36:173-7. doi: 10.1016/j.jcrc.2016.06.033.

8. Chen L, Zhang J, Pan G, Li X, Shi T, He W. Cuffed versus uncuffed endotracheal tubes in pediatrics: A meta-analysis. Open Med 2018;13(1): 366-73. doi: 10.1515/med-2018-0055. 
9. American Heart Association. Pediatric advanced life support provider manual. American Heart Association; 2016. p. 282.

10. Alzahrani A, Al Abbasi S, Abahoussin OK, et al. Prevalence and predictors of out of range cuff pressure of endotracheal and tracheostomy tubes: A prospective cohort study in mechanically ventilated patients. BMC Anesthesiol 2015;15(1):147. doi: 10.1186/s12871-015-91320-7.

11. Tobias J. Pediatric airway anatomy may not be what we thought: Implications for clinical practice and the use of cuffed endotracheal tubes. Paediatr Anaesth 2015;25(1):9-19. doi: 10.1111/pan.12528.

12. Harvie DA, Darvall JN, Dodd M, et al. The minimal leak test technique for endotracheal cuff maintenance. Anaesth Intensive Care 2016;44(5): 599-604. doi: 10.1177/0310057X1604400512.

13. Tsaousi GG, Pourzitaki C, Chlorou D, Papapostolou K, Vasilakos DG. Benchmarking the applicability of four methods of endtracheal tube cuff inflation for optimal sealing: A randomized trail. J Perianesth Nurs 2018;33(2):129-37. doi: 10.106/j.jopan.2016.09.002.

14. Seyed Siamdoust SA, Mohseni M, Memarian A. Endotracheal tube cuff pressure assessment: Education may improve but not guarantee the safety of palpation technique. Anesth Pain Med 2015;5(3):e16163. doi: 10.5812/aapm.5(3)2015.16163.

15. Herbinger L. Evidence based use of cuffed endotracheal tubes in children. J Perianesth Nurs 2018;33(5): 560-600. doi: 10.1016/j.jopan.2017. 07.001.

16. Taylor C, Subaiya L, Corsino D. Pediatric cuffed endotracheal tubes: An evolution of care. Ochsner J 2011;11(1):52-6

17. Tobias JD, Schwartz L, Rice J, Jatana K, Kang DR. Cuffed endotracheal tubes in infants and children: Should we reoutinely measure the cuff pressure? Int J Pediatr Otorhinolaryngol 2011;76(1):61-3. doi: 10.1016/j. ijporl.2011.09.033.

18. Sathyamoorthy M, Lerman J, Okhomina V, Penman A. Use of cuffed tracheal tubes in neonates, infants and children: A practice survey of members of the Society of Pediatric Anesthesia. J Clin Anesth 2016;33: 266-72. doi: 10.1016/j.jclinane.2016.03.013.

19. Valencia M, Ferrer M, Farre R, et al. Automatic control of tracheal tube cuff pressure in ventilated patients in semirecumbent position: A randomized trial. Crit Care Med 2007;35(6):1543-9. doi: 10.1097/01. CCM.0000266686.95843.7D.

20. Suominen P, Taivainen T, Tuominen N, et al. Optimally fitted tracheal tubes decrease the probability of postextubation adverse events in children undergoing general anesthesia. Paediatr Anaesth 2006;16(6): 641-7. doi: 10.1111/j.1460-9592.2005.01832.x.

21. Borazan H, Saritas TB. Predictors of postoperative sore throat in intubated children. Paediatr Anaesth 2012;22(6): 595-6. doi: 10.1111/ j.1460-9592.2012.03864.x.

22. Jain MK, Tripathi CB. Endotracheal tube cuff pressure monitoring during neurosurgery-Manual vs. automatic method. J Anaesthsiol Clin Pharmacol 2011;27(3):358-61. doi: 10.4103/0970-9185.83682.

23. American Thoracic Society. American Thoracic Society: Infectious Disease Society of America. Guidelines for the management of adults with hospital-acquired, ventilator-associated and healthcare-associated pneumonia. Am J Respir Crit Care 2005;171: 388-416. doi: 10.1164/ rccm.200405-644ST.

24. Elward AM, Warren DK, Fraser VJ. Ventilator-associated pneumonia in pediatric intensive care unit patients: Risk factors and outcomes. Pediatrics 2002;109(5):758-64. doi: 10.1542/peds.109.5.758.

25. Lorente L, Lecuona M, Jimenez A, et al. Continuous endotracheal trube cuff pressure control system protects against ventilator-associated pneumonia. Crit Care 2014;18(2):R77. doi: 10.1186/cc13837.

26. Felten M, Schmautz E, Delaporte-Cerceau S, Orliaguet G, Carli P. Endotracheal tube cuff pressuresin pediatric patients intubated before aeromedical transport. Anesth Analg 2003;97(6):1612-6. doi: 10.1213/01. ANE.0000087882.04234.11.

27. Tollefsen W, Chapman J, Gallagher M, Shear M, Thomas S. Endotracheal tube cuff pressures in pediatric patients intubated before aeromedical transport. Pediatr Emerg Care 2010;26(5):361-3. doi: 10.1097/PEC. Ob013e3181db224d.

28. Gilliland L, Perrie H, Scribante J. Endotracheal tube cuff pressures in adult patients undergoing general anaesthesia in two Johannesburg academic hospitals. South Afr J of Anaesth Analg 2015;21(3):81-4. doi: 10.1080/22201181.2015.1056504.

29. Olsen G, Krishna S, Jatana K, Elmaraghy C, Ruda J, Tobias JD. Changes in intracuff pressure of cuffed endotracheal tubes while positioning for adenotonsillectomy in children. Paediatr Anaesth 2016;26(5):500-3. doi: $10.1111 /$ pan. 12873 .

30. Letvin A, Kremer P, Silver PC, Samih N, Reed-Watts P, Kollef MH. Frequent versus infrequent monitoring of endotracheal tube cuff pressures. Respir Care 2018;63(5):495-501. doi: 10.4187/respcare. 05926. 